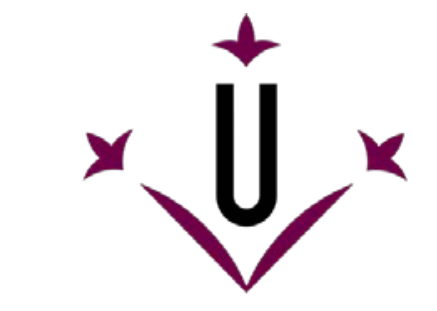

Universitat de Lleida

Document downloaded from:

http://hdl.handle.net/10459.1/62859

The final publication is available at:

https://doi.org/10.1016/i.funbio.2014.11.004

Copyright

(c) The British Mycological Society, 2014 


\section{Effect of ultraviolet radiation $A$ and $B$ on growth and mycotoxin production by Aspergillus carbonarius and Aspergillus parasiticus in grape and pistachio media}

Esther GARCIA-CELA*, Sonia MARIN, Vicente SANCHIS, Ana CRESPO-SEMPERE, Antonio J. RAMOS.

Applied Mycology Unit, Food Technology Department, University of Lleida, UTPV-XaRTA, Agrotecnio Center, Av. Rovira Roure 191, Lleida 25198, Spain

Keywords: A. carbonarius, A. parasiticus, Aflatoxins (AFs), Climate change, Ochratoxin A (OTA), Ozone depletion

\section{Abstract}

The effects of two exposure times per day ( 6 and 16 h) of UV-A or UV-B radiation, combined with dark and dark plus light incubation periods during 7e21 d on fungal growth and mycotoxins production of Aspergillus species were studied. Aspergillus carbonarius and Aspergillus parasiticus were inoculated on grape and pistachio media under diurnal and nocturnal temperatures choosing light photoperiod according to harvest conditions of these crops in Spain. Ultraviolet irradiation had a significant effect on A. carbonarius and A. parasiticus colony size (diameter, biomass dry weight, and colony density) and mycotoxin accumulation, although intraspecies differences were observed. Inhibition of A. carbonarius fungal growth decreased when exposure time was reduced from $16 \mathrm{~h}$ to $6 \mathrm{~h}$, but this was not always true for ochratoxin A (OTA) production. OTA reduction was higher under UV-A than UV$B$ radiation and the reduction increased along time conversely to the aflatoxins (AFs). Aflatoxin $B 1$ (AFB1) was the main toxin produced by $A$. parasiticus except in the UV-B light irradiated colonies which showed a higher percentage of AFG than AFB. Morphological changes were observed in colonies grown under UV-B light.

\section{Introduction}

The last report from the World Meteorological Organization (WMO) highlighted that human emissions of chlorofluorocarbons (CFCs) and other chemicals have an important role in the atmosphere changes by damaging the stratospheric ozone layer that filters out harmful ultraviolet radiation (UV) (WMO 2013). The ozone depletion has a strong link with climate change, as the physics and chemistry of the Earth's atmosphere largely determine our climate, inasmuch changes in ozone can induce changes in climate, and viceversa (McKenzie et al. 2011). For example, changes in atmospheric circulation resulting from climate change can induce regional differences in ozone, leading to increase in UV radiation in some regions and reduction in others (Hegglin \& Shepherd 2009). The United Nations Environment Programme reported that the average of total ozone values for 2006-2009 of about $3.5 \%$ and $2.5 \%$ below than the 1964-1980 averages, for 90S-90N and 60S-60N, respectively (UNEP 2010). Ground-based UV reconstructions and satellite UV retrievals, supported in the later years by direct ground-based UV measurements, show that erythemal ('sunburning') irradiance over midlatitudes has increased since the late 1970s, which is correlated with the observed decrease in column ozone (UNEP 2010). Solar UV radiation transmitted through the earth's atmosphere has three primary streams of incoming radiant flux depending on their 
wavelength range: (i) UV-C (100-280 nm) is the higher energetic portion of the UV spectrum, which does not reach the ground surface as it is completely absorbed by the ozone layer and other atmospheric constituents; (ii) UV-B (280-315 nm) still reaches ground level but it is strongly absorbed by stratospheric ozone; (iii) UV-A (315-380 nm) is only slightly absorbed by ozone layer making up most of the UV irradiance at the ground level (CIE 1987).

Certain groups of filamentous fungi can produce harmful secondary metabolites called mycotoxins. The major groups of mycotoxins, derived from polyketide metabolism, are present in a wide range of foodstuffs: aflatoxins (AFs), fumonisins (FBs), ochratoxin A (OTA) and zearalenone (Gallo et al. 2013). Although the ecological role of mycotoxins is far from being elucidated, several studies indicate the mycotoxin biosynthesis is induced under certain stress conditions (Schmidt-Heydt et al. 2008). Moreover, Cary \& Ehrlich (2006) suggested that AFs production could be a strategy of fungi to prevent from UV damage. Also, citrinin has been considered as a light protectant, since citrinin producing colonies grew better under red and blue light than non-producing colonies (Schmidt-Heydt et al. 2012). However, the effect of UV radiation in mycotoxin biosynthesis is unknown, and to our knowledge there are no publications on this topic.

Some previous works have studied the effect of UV radiation on fungal spore germination, growth, and sporulation, showing that the effect is dependent of time and wavelength of UV exposure (Table 1) (Fourtouni et al. 1998; Moody et al. 1999; Osman et al. 1989; Wu et al. 2000). Fungal spores of Aspergillus flavus and Penicillium chrysogenum are much more resistant to the lethal effects of UV than the vegetative mycelium (Osman et al. 1989). UV-A irradiation stimulated fungal growth of several species while in others species it had no influence on radial growth or dry mass (Fourtouni et al. 1998; Moody et al. 1999; Osman et al. 1989). The UV-B irradiation not only reduced the germination and sporulation in most of the fungi tested but also reduced the colony diameter (Aylor and Sanogo, 1997; Fourtouni et al. 1998; Moody et al. 1999). This contrast between the responses of fungi to these two different parts of the UV region can be explained by the fact that shorter wavelength radiations are more deleterious to biological systems as they carry more energy per photon than longer wavelengths (Moody et al. 1999).

The aim of this study was to assess the effect of UV-A and UV-B radiation on fungal growth and mycotoxin (OTA/AFs) production of two Aspergillus species commonly isolated in foodstuffs: the OTA producer Aspergillus carbonarius which is present mainly in vineyards around the world and the AFs producer Aspergillus parasiticus which is frequently isolated from tree nuts, as pistachio (Denizel et al. 1976; García-Cela; Jamali et al. 2012). For that purpose three experiments were carried out focussing on i) evaluation of the effect of cycles of UV radiation/darkness on $\mathrm{A}$. carbonarius; ii) the effect of cycling UV radiation/white light/darkness on A. carbonarius; iii) the effect of cycles of UV radiation/white light/darkness on $A$. parasiticus. Experiments ii) and iii) were launched trying to simulate field temperature and photoperiod conditions.

\section{Materials and methods}

Microorganisms, growth medium, and inoculation 
This work was carried out on three Aspergillus carbonarius (311, 318, 287-UdLTA) isolates coming from grapes and one Aspergillus parasiticus (3.18-UdLTA) from the culture collection of the Food Department of Lleida University. Different culture media were used for each species simulating commodities from which these species are commonly isolated: Synthetic Nutrient Medium of grape (SNM) and Pistachio Based Medium (PBM), respectively. Composition of SNM is similar to grape composition between veraison and ripeness (Delfini 1982). For PBM preparation, $30 \mathrm{~g}$ of pistachio were ground and boiled in $1 \mathrm{~L}$ of distilled water for $30 \mathrm{~min}$. Subsequently, the extract was filtered with a gauze made up to $1 \mathrm{~L}$ with water. Additionally, 15 $\mathrm{g}$ of agar were added. After that, the medium was autoclaved for $15 \mathrm{~min}$ at $121{ }^{\circ} \mathrm{C}$. For each experiment, the isolates were sub-cultured on SNM or PBM plates and incubated at $25{ }^{\circ} \mathrm{C}$ for 7 $\mathrm{d}$ to obtain heavily sporulating cultures. Following incubation, a sterile inoculation loop was used to remove the conidia, suspending them in Tween 80 (0.005\%). After homogenizing, the suspensions were adjusted using a Thoma counting chamber to a final concentration of 105 conidia/mL in Tween 80 and $5 \mathrm{~mL}$ of suspension were inoculated in the middle of the Petri dishes.

\section{Experimental design and incubation conditions}

Two different combinations of UV radiation time exposure ( 16 and $6 \mathrm{~h}$ ) were assessed on Aspergillus carbonarius. Additionally the shortest period was also studied on Aspergillus parasiticus. Firstly, in order to determine the effect of UV radiation on three $A$. carbonarius isolates (287-UdLTA, 311-UdLTA, 318-UdLTA), inoculated Petri dishes were incubated at 25 ㄷ for $21 \mathrm{~d}$. Petri dishes used as control were incubated under darkness while irradiated Petri dishes were incubated under a photoperiod of $16 \mathrm{~h}$ of UV radiation (UV-A or UV-B) and $8 \mathrm{~h}$ of darkness. Fungal diameter of six Petri dishes of each isolate was measured every $7 d$ and then three of them were used for biomass weight determination and the other three for OTA production analysis. Additionally, the second experiment was carried out with the same three A. carbonarius isolates but incubated for $7 \mathrm{~d}$ under the photoperiod and temperature conditions described in Fig $1 \mathrm{~A}$. At the end of the incubation period colony diameters were measured and $A$. carbonarius colonies from three Petri dishes of each isolate were then divided in two equal parts one for quantification of biomass weight and the other one for OTA production analysis. In a third experiment, A. parasiticus (3.18-UdLTA) was incubated for $7 \mathrm{~d}$ under the photoperiod and temperature conditions described in Fig 1B, plus full dark incubation as a control. Colony diameters were measured in two Petri dishes on days 3,5 , and 7. Subsequently, colonies were divided in two equal parts, one for fungal biomass and one for AFs determination. Photoperiod and temperatures were chosen concurring with grape (August) and pistachio (September) ripening in Spain. Photoperiod values were obtained from the National Spanish Geographic Institute (IGN), while temperatures were obtained from the Meteorological Spanish Association (AEMET). With the aim to simulate dawn and dusk and the consequent gradient of temperature between night and day, the incubators were set in a temperature gradient mode based on temperature increasing period (dawn) and a temperature decreasing period (dusk) linked by two constant periods simulating day and night temperatures (Fig 1).

Irradiated and non-irradiated Petri dishes were incubated in parallel under the same conditions of time and temperature in two incubators (Memmert ICP-600, United Kingdom). 
Diurnal illumination was simulated with four cold white fluorescent lights (standard illuminant D65, $6500 \mathrm{~K}$ ) located in the incubators. UV irradiation was generated with a Vilber Lourmat lamp VL-215.LM (Germany). The lamp includes two fluorescent tubes of $15 \mathrm{~W}$ each one and a filter that minimizes light interferences. UV-A extends from 320 to $400 \mathrm{~nm}$ with an energy peak at $365 \mathrm{~nm}$ and UV-B runs from 280 to $370 \mathrm{~nm}$ with an energy peak at $312 \mathrm{~nm}$ (Fig 2). Irradiated Petri dishes were located at 8 and $32 \mathrm{~cm}$ of distance from the UV-A and UV-B lamps, resulting in an irradiation of $1.7+/-0.2 \mathrm{~mW} / \mathrm{cm} 2$ and $0.1+/-0.2 \mathrm{~mW} / \mathrm{cm} 2$ for UV-A and UV-B, respectively. The irradiation was measured with a portable UV light meter (UVAUVB PCE-UV34, PCE Iberica S.L, Spain).

Values of radiant energy were chosen taking into account annual values from the South of Spain, which has a high number of annual hours of sun. Ultraviolet irradiation was measured for 11 daily hours (from 7:00 to 18:00 h) for 5 y (Ortega et al. 2001). Monthly measures of maximum, mean, and minimal UV-A and UV-B global (direct and diffused) radiation in hourly intervals (1991e1995) in South Spain and experimental irradiation used in this study are showed in Fig 3. The maximum and minimum UV irradiations were measured in July and in December, respectively. Moreover, the lower UV irradiation values were recorded between 17 and $18 \mathrm{~h}$ while the higher values were between 12 and $14 \mathrm{~h}$ GMT (GMT: Greenwich Mean Time). Annual values for UV-A ranged from $0.06 \mathrm{~mW} / \mathrm{cm} 2$ to $2.49 \mathrm{~mW} / \mathrm{cm} 2$ with a mean value of $1.17 \mathrm{~mW} / \mathrm{cm} 2$, while for UV-B they were from $<0.001 \mathrm{~mW} / \mathrm{cm} 2$ to $0.23 \mathrm{~mW} / \mathrm{cm} 2$ with a mean value of $0.09 \mathrm{~mW} / \mathrm{cm} 2$. Considering the doses and the exposure time, the daily accumulated UV-A and UV-B radiation in the experiments was of $0.367 \mathrm{MJ} / \mathrm{m} 2$ and 0.022 $\mathrm{MJ} / \mathrm{m} 2$ respectively. Whereas the mean daily accumulated annual UV-A radiation was 0.464 $\mathrm{MJ} / \mathrm{cm} 2$, and focussing on harvest months values were $0.632 \mathrm{MJ} / \mathrm{cm} 2$ in August and 0.539 $\mathrm{MJ} / \mathrm{cm} 2$ in September. The UV-B mean daily accumulated annual values were $0.035 \mathrm{MJ} / \mathrm{cm} 2$ and $0.050 \mathrm{MJ} / \mathrm{cm} 2$ in August and $0.045 \mathrm{MJ} / \mathrm{cm} 2$ in September.

In conclusion, direct UV doses used in the study were slightly higher than the global (direct $p$ diffuse) UV mean values recorded in South Spain, but daily accumulated irradiation was lower due to the less number of hours of exposure.

Growth assessment: colony diameter and fungal biomass

Fungal growth was determined by measuring two perpendicular diameters for each colony. Mycelium dry weight was measured as mentioned in Taniwaki et al. (2006) on culture medium. Briefly, colonies were cut from the medium, transferred to a beaker containing distilled water (100 $\mathrm{mL}$ approximately), and heated in a streamer for $30 \mathrm{~min}$ for agar melting.

The intact mycelium was collected and transferred to a dried, weighed filter paper and dried at 80 ㅇ $\mathrm{C}$ for $18 \mathrm{~h}$. Then the filter paper plus the colony were weighed and the dry weight of biomass was calculated by difference.

Mycotoxin extraction and quantification

Two or three agar plugs $(5 \mathrm{~mm}$ ) depending on the colony size were removed from the middle to the outer part of the colony, placed in a vial and weighed. Mycotoxins were extracted by adding $1 \mathrm{~mL}$ of methanol into the vials, shaken for $5 \mathrm{~s}$ and allowed to rest. After $60 \mathrm{~min}$, the 
vials were shaken again and the extract filtered (OlimPeak filters by Teknokroma PVDF Filter, $0.45 \mathrm{~mm}, 13 \mathrm{~mm} \mathrm{D}$, Sant Cugat del Valles, Barcelona, Spain) into another vial. Subsequently, the extract was evaporated under a stream of nitrogen and stored at $4 \stackrel{\circ}{ } \mathrm{C}$ until HPLC analysis (Waters, Mildford, Ma, S.A.). Prior to HPLC injection, dried extracts were dissolved in $1 \mathrm{~mL}$ ofmethanol: water (50:50). A HPLC system (Waters 2695, separations module, Waters, Milford, USA) equipped with a fluorescence detectorWaters 2475 module (Waters, Milford, USA), precolumn Waters Spherisorb $5 \mathrm{~mm}$, ODS2, 4.6x10 mm, and a C18 silica gel column (Waters Spherisorb $5 \mathrm{~mm}$, ODS2, 4.6×250 mm, Millford, MA, USA) kept at 40 ㄷ $\mathrm{C}$ were used. For AFs a post column photochemical derivatization system (LC Tech detector, UVC $254 \mathrm{~nm}$, Germany) was used. Mobile phases were acetonitrile:water: acetic acid (57:41:2) for OTA and water: methanol: acetonitrile (70:17:17) for AFs, and were pumped at $1 \mathrm{~mL} \mathrm{~min}-1$ under isocratic conditions. Mycotoxins were quantified on the basis of the HPLC fluorimetric response (OTA:

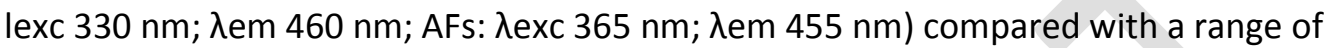
mycotoxin standards. Detection limits of $0.01 \mathrm{ng} \mathrm{g}-1$ for OTA, of $0.02 \mathrm{ng}$ g- 1 for aflatoxins B2 and $\mathrm{G} 2$, and of $0.04 \mathrm{ng}$ g-1 for aflatoxins B1 and G1, were established based on a signal-tonoise ratio of 3:1. Quantification was achieved with a software integrator (Empower, Milford, MA, USA).

Statistical analysis

Results were analysed by one-way ANOVA followed by the Tukey's honestly significant different test (HSD), using StatgraphicsCenturion XVI (USA). The level of significance was defined as $p<0.05$.

\section{Results}

Effect of UV-A and UV-B radiation/darkness on A. carbonarius (exp.1) In this experiment, three Aspergillus carbonarius isolates were incubated at $25 \stackrel{\circ}{ } \mathrm{C}$ for $21 \mathrm{~d}$ under darkness or under $16 \mathrm{~h}$ of UV radiation/8 $\mathrm{h}$ darkness. Under UV-A radiation/darkness cycles, colony diameters, biomass dry weight, and OTA production were reduced compared to dark treatment both on day 14 and 21 ( $p<0.05$ ) (Fig 4, Table 2 ). Colony density was calculated dividing biomass dry weight by colony area for each time period. Density values ranged from 0.04 to $0.09 \mathrm{mg} / \mathrm{mm} 2$ in the control treatment and from 0.03 to $0.16 \mathrm{mg} / \mathrm{mm} 2$ in irradiated colonies with the exception of the isolate $318-U d L T A$ which reached $0.61 \mathrm{mg} / \mathrm{mm} 2$ under UV-A radiation.

Control colonies were less dense than the irradiated ones on day 14, but this difference was reduced after $21 \mathrm{~d}$. Significant differences were found among strains in colony diameter and OTA production but not in biomass dry weight. Besides, OTA concentration decreased with the time. The mean percentages of reduction for colony diameter, biomass dry weight, and OTA production were $78.9 \%, 75.5 \%$, and $89.1 \%$ when isolates were cultivated under UV-A radiation for $14 \mathrm{~d}$ and $38.4 \%, 59.3 \%$, and $96.9 \%$ when the incubation period was $21 \mathrm{~d}$. The isolate 287-UdLTA was less affected by the UV-A radiation than the other two isolates of A. carbonarius tested, in terms of colony diameter and biomass dry weight. Besides, OTA production by this isolate after $14 \mathrm{~d}$ was significantly higher than the others. Regarding UV-B light, colony diameters, biomass dry weight, and OTA production were reduced, compared to the control treatment (darkness incubation) while incubation time and isolate differences had no significant impact ( $p<0.05$ ) (Fig 5 , Table 2 ). Colony density values ranged from 0.03 to 0.05 
$\mathrm{mg} / \mathrm{mm} 2$ in non-irradiated and $0.01-0.09 \mathrm{mg} / \mathrm{mm} 2$ in irradiated colonies except for the isolate 318-UdLTA under UV-B light which was significantly denser than the other isolates (1.84 $\mathrm{mg} / \mathrm{mm} 2$ ). The mean percentages of reduction for colony diameter, biomass dry weight, and OTA production were $37.7 \%, 70.5 \%$, and $55.7 \%$ when isolates were incubated under UV-B radiation for $14 \mathrm{~d}$, and $52.3 \%, 20.4 \%$, and $82.1 \%$ when the incubation period was $21 \mathrm{~d}$. Bigger colonies and higher mycotoxin production were observed after incubation under UV-B radiation than under UVA radiation. Contrary to UV-A radiation the isolate 311-UdLTA was the less affected. Therefore, the isolate sensitivity would depend on UV wavelength. UV-B irradiation caused milder inhibitory effects than UV-A irradiation, however, it affected the colony morphology. Sporulation was only observed in the center of the colonies, in fact, this part was harder and more compact than in non-irradiated colonies. Besides, under the microscope, neither conidia nor conidiophores were observed in the surrounding growing colony area.

Effect of UV radiation/light and dark cycles on A. carbonarius (exp. 2)

Three Aspergillus carbonarius isolates were incubated for $7 \mathrm{~d}$ under the photoperiod and temperature cycles described in Fig 1. Irradiation had a significant effect on diameter, biomass dry weight, and OTA accumulation, but intraspecies differences affected colony size and OTA production (Table 3). Significant differences on density were only observed under UV-B irradiation, where density mean value in control Petri dishes was of $0.10 \mathrm{mg} / \mathrm{mm} 2$ against mean value of $0.02 \mathrm{mg} / \mathrm{mm} 2$ on irradiated ones. Percentages of reduction were $35.3 \%, 53.3$ $\%$, and $97.0 \%$ for UV-A, and $16.8 \%, 77.16 \%$, and $81.9 \%$ for UV-B in terms of colony diameter, biomass dry weight, and OTA production, respectively (Fig 6). UVB radiation affected the colony morphology as observed in experiment 1 . Sporulation was observed only in the center of colonies, which was harder and more compacted than the rest of the colony.

Comparing with the previous experiment, colony diameter, and fungal biomass dry weight of A. carbonarius UV irradiated for $16 \mathrm{~h}$ and incubated at $25{ }^{\circ} \mathrm{C}$, did not exceed $10 \mathrm{~mm}$ and $40 \mathrm{mg}$ under UV-B radiation (data not shown), respectively, after $7 \mathrm{~d}$. Hence, a decrease in the UV time exposure reduced also the deleterious effects on A. carbonarius. Moreover, when comparing the controls of both experiments, that is, incubation under full darkness (exp. 1) and darkness and light cycles (exp. 2), higher values of fungal growth and OTA production were reached when white light was included. However it should be taken into account that, different temperature regimes were applied and therefore these differences could not only be attributed to light conditions but also to temperature or the combination of both variables.

Effect of UV radiation/light and dark cycles on A. parasiticus (exp. 3)

One Aspergillus parasiticus isolate (3.18-UdLTA) was incubated on PBM for $7 \mathrm{~d}$ under the temperature cycles described in Fig 1, plus full dark incubation as an additional control. UVA irradiation had a significant effect on colony diameter compared to full darkness. In the case of AFs production significant differences were found between irradiated and nonirradiated treatments (Table 4, Fig 7). In addition, biomass dry weight differences were also significant from day 5 in the case of UV-B. Nevertheless, no significant differences were observed in colony density due to the UV radiation, with mean values of $0.05 \mathrm{mg} / \mathrm{mm} 2$. The present experiment included the comparison between full dark period and light/dark without UV light; 
the results showed no differences between these two treatments, this fact suggests that the differences shown can be fully attributed to UV-light and not to white light.

Comparing both wavelengths, higher percentages of reduction were observed in colonies irradiated with UV-B than UV-A radiation compared to non-irradiated ones (Fig 7). Moreover, under UV-A light, percentages of reduction of colony diameter (from 21.43 to $5.41 \%$ ), and biomass dry weight (from 36.51 to $9.60 \%$ ) decreased along the time. Conversely, under UV-B radiation percentages of reduction of colony diameter (from $48.48 \%$ to $73.68 \%$ ) and biomass dry weight (from 26.98 to $96.02 \%$ ) increased with time. These results could indicate Some adaptation to UV-A, whilst UV-B radiation would practically stop fungal metabolism.

Interestingly, high significant differences due to the UV radiation were found for AFs production (Fig 7). Kinetics of AFs production without UV-light showed the maximum production in the 5-7th day, while under UV-A AFs concentration did not change with time and under UV-B the maximum AFs level was recorded in the 7th day. AFB1, AFB2, AFG1, and AFG2 contribution to total AFs was quite constant except under UV-B (Fig 8). In general, AFB2 and AFG2 were produced in lower amount while AFB1 always presented values over $65 \%$ of the total AFs production. However, under UV-B light a higher percentage of AFG than AFB was recorded. As observed, for $A$. carbonarius, mycelium morphology changed under different light conditions. Six hours of UV-B radiation practically inhibited the aerial mycelium, and conidia were not observed after $7 \mathrm{~d}$. Colonies under UV-A radiation showed a dense centre, high development of aerial mycelium on the periphery of colony and tiny areas without visible growth inside the colony. Colonies incubated under cycles of light/darkness were more heavily sporulated and appeared more coloured than those grown under darkness or UV-A light/darkness.

\section{Discussion}

The biological consequences of ozone depletion, mediated through an increase in UV-B radiation, have been cause for concern for many years. However, there is not much information about the ecological response to the hypothetically increasing solar UV radiation in fungi and specifically in mycotoxigenic fungi. Spain is not only the European country that receives the greater amount of radiation but also the country that shows the greatest contrast and radiative gradients and complexity in the distribution of the radiative energy (AEMET 2012). Values used in this study concerned to mean values of UV-A and UV-B global (direct and diffused) radiation measured in Seville, since this city has one of the greatest intensity of radiation and number of hours of exposure values.

In this work, the effect of UV-A $(365 \mathrm{~nm})$ and UV-B $(312 \mathrm{~nm})$ radiation on fungal growth and mycotoxin production of Aspergillus carbonarius and Aspergillus parasiticus, which are frequently isolated from crops, has been studied. Crop simulation media were chosen since irradiation has been shown to have different effects depending on the microbial growth media due to the potentially protective nutrient presence (Osman et al. 1989).

The UV-A radiation (315-380 $\mathrm{nm}$ ) is only slightly absorbed by the ozone layer, most reaching the ground level (CIE 1987). In fact, UV-A radiation is an important environmental factor for sporulation in many fungi (Elad 1997; Fourtouni et al. 1998; Osman et al. 1989; Nicot et al. 
1996). Irradiance at $0.04 \mathrm{~mW} / \mathrm{cm} 2(366 \mathrm{~nm})$ decreased the germination but increased colony radial growth rate of Penicillium notatum after up to $20 \mathrm{~min}$ of exposure, while longer periods of irradiation reduced colony development (Osman et al. 1989). By contrast, $12 \mathrm{~h}$ exposure (0.051-0.167 mW/cm2) for $7 \mathrm{~d}$ had no influence on radial growth or dry mass weight in Alternaria solani despite spore production increased significantly (Fourtouni et al. 1998). Similarly, $3 \mathrm{~h}$ photoperiod ranging from 3.056 to $5.556 \mathrm{~mW} / \mathrm{cm} 2$ at a wavelength of 315-400 $\mathrm{nm}$ caused a significant enhancement of germination of Penicillium purpurogenum spores while significantly reduced germination of conidia of Cladosporium cladosporioides (Moody et al. 1999). Sporangia exposed to irradiance of $1.25 \mathrm{~mW} / \mathrm{cm} 2$ of UV-A $(340-350 \mathrm{~nm}$ ) for $8 \mathrm{~h}$ showed reduced germination compared to the sporangia that remained in the dark (Wu et al. 2000). In the present work, we have observed for Aspergillus a significant reduction on mycelium and mycotoxins when irradiated for $6 \mathrm{~h}$ at $1.7 \mathrm{~mW} / \mathrm{cm} 2$. Sixteen hours of exposure at the same irradiation reduced significantly the OTA contamination detected along the time.

Although UV-B radiation is for less than $1 \%$ of the total energy of the electromagnetic spectrum, it is a highly active component of the solar radiation that can produce chemical modifications in DNA changing its molecular structure by the formation of dimers (Rastogi et al. 2010). Therefore, this radiation may directly damage the exposed tissues of plant pathogens, including spores during dispersal (Rotem et al. 1985; Wu et al. 2000). As for UV-A, different impact of UV-B on fungi is found in the literature. Exposure to $0.019 \mathrm{~mW} / \mathrm{cm} 2$ (292e350 $\mathrm{nm}$ ) consistently reduced spore germination and mycelial extension rates in Aspergillus fumigatus, Penicillium hordei, Penicillium janczewskii, Penicillium spinulosum, and Penicillium purpurogenum, while inhibitory effects were lower in Mucor hiemalis, Cladosporium cladosporioides, Leptosphaeria coniothyrium, Nectria inventa, Trichoderma viride, Ulocladium consortiale, and Marasmius androsaceus (Moody et al. 1999). Bremia lactucae was exposed to two elevated irradiation doses, 0.150 and $0.700 \mathrm{~mW} / \mathrm{cm} 2$, from 2 to $12 \mathrm{~h}$ (Wu et al. 2000).

Both irradiations reduced significantly the percentage of germination of the incubated isolates under white light $(0.4 \mathrm{~mW} / \mathrm{cm} 2)$ or under complete darkness. Moreover, after $8 \mathrm{~h}$ of exposure to the highest irradiation the germination was practically inhibited. We observed that 0.1 $\mathrm{mW} / \mathrm{cm} 2$ reduced all fungal parameters studied on Aspergillus. Additionally, an increase on the UV-B radiation exposure time on $A$. carbonarius, increased the deleterious effects. Although different media and temperature regimes were used, $A$. carbonarius showed higher resistance to UV-B irradiation than $A$. parasiticus. As intraspecific differences were found in the response of the different $A$. carbonarius strains, the results for the $A$. parasiticus strain should not be extrapolated to the species level.

The effect of UV-A and UV-B was not compared as both radiations were applied at different levels of intensity. However, it could be that UV-A supported some kind of mutagenic adaption of the fungus while the UV-B, as it is much stronger, led to the stop of fungal growth and metabolism, although no previous information on this has been found in the literature to support this hypothesis.

Different tolerances to the deleterious effect of solar UV radiation on fungi have been reported before. Rotem et al. (1985) found that mortality due to solar UV radiation increased from A. solani to Ulocladium phaseoli to Peronospora tabacina. Osman et al. (1989) suggested 
that differences in sensitivity may be attributed to spore colour. These authors pointed out that the resistance of pigmented conidia to the lethal effects of UV irradiation may be due to the action of pigments as quenchers to singlet oxygen produced by photosensitive compounds in fungal cells. Furthermore, Grishkan et al. (2003) found a significant correlation between areas receiving high solar irradiation and the incidence of melanin-containing fungal species among soil microfungi isolated in Israel.

It is worthy to mention that mycelium morphology changed due to UV-B exposure, as the colonies produced pigmented compact mycelium in the center of the colony and submerged mycelium at the periphery. This tendency was also observed in A. solani by Fourtouni et al. (1998), where the authors suggested that the fungi employs mainly a morphological (i.e., increased density) rather than chemical (i.e., UVB absorbing compounds) protective strategy against UV-B radiation damage. Therefore, the submerged growth could be a fungal strategy against radiation since minimal doses of UV-B penetrate into the medium (Fourtouni et al. 1998).

In conclusion, UV radiation is an interesting abiotic natural factor which could affect not only survival and growth of fungi but also secondary metabolites production. In this study, A. carbonarius showed a great UV resistance even during prolonged periods of direct UV exposure of $12 \mathrm{~h}$ (exp 1). This provides a logical explanation for the high numbers of $A$. carbonarius on grapes subjected to prolonged sun exposure in countries with high UV irradiance as Spain, Italy or Greece (Battilani et al. 2006; García-Cela et al. 2014; Tjamos et al. 2006).

On the other hand, it is widely accepted that stress conditions could promote the mycotoxin production. However, from our results UV radiation always reduced OTA and AFs ontamination compared to non-irradiated colonies probably as a result of a decreased growth. Nonetheless, the possible degradation to other compounds was not evaluated, as it occurs on maize, where a natural transformation from transzearalenone (ZEN) to cis-ZEN after $24 \mathrm{~h}$ of UV-A irradiation (3.2 mW/cm2) can occur (Brezina et al. 2013). Similarly, incubation of A. carbonarius under two simulated climatic conditions characterized by alternating temperature cycles (10/25 $\circ \mathrm{C}$ and $15 / 35 \circ \mathrm{C})$ with photoperiod (14/10 h lightness/darkness), and two moisture levels ( $40 \%$ and $25 \%$ ) for $21 \mathrm{~d}$, showed that the extreme conditions tested caused a significant OTA reduction contamination (García-Cela et al. 2012). Therefore, Aspergillus presence on crops under future climate conditions proposed by Southern Europe (EC 2007), could not be compromised; although the mycotoxin risk in vivo derived from predicted climatic conditions characterized by high temperatures, drier conditions, and increased UV could be reduced.

It must be noted that in these in vitro studies, plant stress is not taken into account, and this stress situation could led to an increased fungal colonisation. Nevertheless, fungal presence per se represents an important risk, because favourable conditions for toxin production can occur in the following postharvest stages.

\section{Acknowledgements}


The authors are grateful to the Spanish Government (AGL2010-22182-C04-01) and Comissionat per a Universitats I Recerca del Departament d'Innovacio, Universitats i Empresa de la Generalitat de Catalunya (AGAUR). The authors are also grateful to Fernando Rubio and Hector Castan by the laboratory support.

\section{References}

Agencia Española de Meteorología (AEMET), 2012. Atlas de radiación solar en España utilizando datos del SAF de clima de EUMETSAT.

Agencia Estatal de Meteorología.

http://www.aemet.es/documentos/es/serviciosclimaticos/datosclimatologicos/atlas_radiacion _solar/atlas_de_radiacion_24042012.pdf.

Agencia Española de Meteorología (AEMET). 2014 Datos climáticos. Available from: http://www.aemet.es/es/serviciosclimaticos/datosclimatologicos.

Aylor DE, Sanogo S, 1997. Germinability of Venturia inaequalis conidia exposed to sunlight. Phytopathology 87: 628-633.

Battilani P, Barbano C, Rossi V, Bertuzzi T, Pietri A, 2006. Spatial distribution of ochratoxin A in vineyard sampling design to assess must contamination. Journal of Food Protection 69: 884890.

Brezina U, Kersten S, Valenta H, Sperfeld P, Riedel J, D€anicke S, 2013. UV-induced cis-trans isomerization of zearalenone in contaminated maize. Mycotoxin Research 29: 221-227.

Cary JW, Ehrlich KC, 2006. Aflatoxigenicity in Aspergillus: molecular genetics, phylogenetic relationships and evolutionary implications. Mycopathologia 162: 167-177.

CIE, 1987. International Lighting Vocabulary, 4th edn. Commission Internationale de L’Eclariage. Delfini C, 1982. Tecnica di microbiologia enologica. Luigi Scialpi, Roma.

Denizel T, Jarvis B, Rolfe EJ, 1976. A field survey of pistachio (Pistacia vera) nut production and storage in Turkey with particular reference to aflatoxin contamination. Journal of the Science of Food and Agriculture 27: 1021-1026.

Elad Y, 1997. Effect of filtration of solar light on the production of conidia by field isolates of Botrytis cinerea and on several diseases of greenhouse-grown vegetables. Crop Protection 16: 635-642.

European Commission, 2007. Adapting to Climate Change in Europe. Options for EU Action Green Paper from the Commission tothe Council, the European Parliament, the European Economic and Social Committee of the Regions, SEC 849, COM 354 Final.

European Commission, Brussels. Fourtouni A, Manetas Y, Christias C, 1998. Effects of UV-B radiation on growth, pigmentation, and spore production in the phytopathogenic fungus Alternaria solani. Canadian Journal of Botany 76: 2093-2099. 
Gallo A, Ferrara M, Perrone G, 2013. Phylogenetic study of polyketide synthases and nonribosomal peptide synthetases involved in the biosynthesis of mycotoxins. Toxins 5: 717742.

García-Cela E, Crespo-Sempere A, Gil-Serna, Porqueres A, Marin S, 2014. Fungal diversity, incidence and mycotoxin contamination in grapes from two agro-climatic Spanish regions with emphasis on Aspergillus species. Journal of the Science of Food and Agriculture.

http://dx.doi.org/10.1002/jsfa6876 In press. Published online in Wiley Online Library: wileyonlinelibrary.com

García-Cela E, Gil-Serna J, Marın S, Acevedo H, Pati no B, Ramos AJ, 2012. Effect of preharvest anti-fungal compounds on Aspergillus steynii and $A$. carbonarius under fluctuating and extreme environmental conditions. International Journal of Food Microbiology 159: 167-176.

Grishkan I, Nevo E, Wasser SP, Beharav A, 2003. Adaptive spatiotemporal distribution of soil microfungi in «Evolution Canyon » II, Lower Nahal Keziv, western Upper Galilee, Israel.

Biological Journal of the Linnean Society 78: 527-539.

Hegglin MI, Shepherd TG, 2009. Large climate-induced changes in ultraviolet index and stratosphere-to- troposphere ozone flux. Nature Geoscience 2: 687-691.

IGN, Spanish Geographic National Institute Available from: 2014 http://www.fomento.es/MFOM/LANG_CASTELLANO/DIRECCIONES_GENERALES/INSTITUTO_G EOGRAFICO/Astronomia/publico/efemerides/salida_puesta_sol.htm.

Jamali M, Ebrahimi M-A, Karimipour M, Shams-Ghahfarokhi M, Dinparast-Djadid N, Kalantari S, Pilehvar-Soltanahmadi Y, Amani A, Razzaghi-Abyaneh M, 2012. An insight into the distribution, genetic diversity, and mycotoxin production of Aspergillus section Flavi in soils of pistachio orchards. Folia Microbiologica 57: 27-36.

McKenzie RL, Aucamp PJ, Bais AF, Bj€orn LO, llyas M, Madronich S, 2011. Ozone depletion and climate change: impacts on UV radiation. Photochemical and Photobiological Sciences 10: 182198.

Moody SA, Newsham KK, Ayres PG, Paul ND, 1999. Variation in the responses of litter and phylloplane fungi to UV-B radiation (290-315 nm). Mycological Research 103: 1469-1477.

Nicot PC, Mermier M, Vaissi ere BE, Lagier J, 1996. Differential spore production by Botrytis cinerea on agar medium and plant tissue under near-ultraviolet light-absorbing polyethylene film. Plant Disease 80: 555-558.

OrtegaM, Martín FJ, Camacho F, 2001. Medidas de la radiacion solar ultravioleta en Sevilla. Actas Dermosifiliograficas 92: 271-275.

Osman M, Elsayed MA, Mohamed YAH, Abo-Zeid AM, 1989. Effect of ultraviolet irradiation on germination and growth in Aspergillus flavus and Penicillium notatum. Mycological Research 92: 293-296. 
Rastogi RP, Richa, Kumar A, Tyagi MB, Sinha RP, 2010. Molecular mechanisms of ultraviolet radiation-induced DNA damage and repair. Journal of Nucleic Acids 2010.

http://dx.doi.org/10.4061/2010/592980 Article IC 592980, 32 pages.

Rotem J, Wooding B, Aylor DE, 1985. The role of solar radiation, especially ultraviolet, in the mortality of fungal spores. Phytopathology 75: 510-514.

Schmidt-Heydt M, Magan N, Geisen R, 2008. Stress induction of mycotoxin biosynthesis genes by abiotic factors. FEMS Microbiology Letters 284: 142-149.

Schmidt-Heydt M, Cramer B, Graf I, Lerch S, Humpf H-U, Geisen R, 2012. Wavelengthdependent degradation of ochratoxin and citrinin by light in vitro and in vivo and its implications on Penicillium. Toxins 4: 1535-1551.

Taniwaki MH, Pitt JI, Hocking AD, Fleet GH, 2006. Comparison of hyphal length, ergosterol, mycelium dry weight and colony diameter for quantifying growth of fungi from foods. In: Hocking AD, Pitt JI, Samson RA, Thrane U (eds), Advances in Food Mycology. Springer, New York, pp. 49-67.

Tjamos SE, Antoniou PP, Tjamos EC, 2006. Aspergillus spp., distribution, population composition and ochratoxin A production in wine producing vineyards in Greece. International Journal of Food Microbiology 111: 61-66.

UNEP, 2010. Scientific Assessment of Ozone Depletion: 2010 World Meteorological Organization Global Ozone Research and Monitoring ProjectdReport No. 52 Scientific Assessment of ozone Depletion: 2010 Pursuant to Article 6 of the Montreal Protocol on Substances that Deplete the Ozone Layer National

Oceanic and Atmospheric Administration National Aeronautics and Space Administration United Nations Environment Programme World Meteorological Organization European Commission Available from:

http://www.esrl.noaa.gov/csd/assessments/ozone/2010/chapters/chapter2.pdf

WMO, 2013. The Global Climate 2001e2010 a Decade of Climate Extremes Summary Report. World Meteorological Organization, Available from: http://library.wmo.int/pmb_ged/wmo_1119_en.pdf.

Wu BM, Subbarao KV, Van Bruggen AHC, 2000. Factors affecting the survival of Bremia lactucae sporangia deposited on lettuce leaves. Phytopathology 90: 827-833. 


\section{Figures}

Fig 1. Incubation conditions for (A) A. carbonarius on SNM (synthetic nutrient grape) and (B) A. parasiticus on PBM (pistachio based medium). UV-A irradiation $1.7 \pm 0.2 \mathrm{~mW} / \mathrm{cm}^{2}$ and UV-B irradiation $0.1 \pm 0.2 \mathrm{~mW} / \mathrm{cm}^{2}$.

Fig 2. Ultraviolet emission spectra for the UV lamps.

Fig 3. Monthly measures of maximum, mean and minimal UV-A and UV-B global (direct and diffused) radiation in hourly intervals (1991-1995) in Seville and experimental irradiation used in this study.

Fig 4. Colony diameters, biomass dry weight, and OTA (ochratoxin A) production of $A$. carbonarius (287-UdLTA, 311-UdLTA, and 318-UdLTA) on SNM at $25^{\circ} \mathrm{C}$. Control Petri dishes were incubated under darkness while irradiated Petri dishes were incubated under photoperiod of $16 \mathrm{~h}$ of UV-A radiation $\left(1.7 \pm 0.2 \mathrm{~mW} / \mathrm{cm}^{2}\right)$ and $8 \mathrm{~h}$ of darkness. Different letters mean significant differences according to Tukey (HSD) test.

Fig 5. Colony diameters, biomass dries weight, and OTA (ochratoxin A) production of $A$. carbonarius (287-UdLTA, 311-UdLTA, and 318-UdLTA) in SNM (synthetic nutrient medium) at $25{ }^{\circ} \mathrm{C}$. Control Petri dishes were incubated under darkness while irradiated Petri dishes were incubated under photoperiod of $16 \mathrm{~h}$ of UV-B radiation $(0.1 \pm 0.2 \mathrm{~mW} / \mathrm{cm} 2)$ and $8 \mathrm{~h}$ of darkness. Different letters mean significant differences according to Tukey (HSD) test.

Fig 6. Colony diameters, biomass dry weight, and OTA (ochratoxin A) production by A. carbonarius (287-UdLTA 311-UdLTA and 318-UdLTA) on SNM (synthetic nutrient medium) after $7 \mathrm{~d}$ under incubated conditions presented in Fig 1 . Irradiation doses are $1.7 \pm 0.2 \mathrm{~mW} / \mathrm{cm} 2$ and $0.10 \pm 0.2 \mathrm{~mW} / \mathrm{cm} 2$ for UV-A and UV-B. Different letters mean significant differences according to Tukey (HSD) test.

Fig 7. Colony diameters, biomass dry weight, and aflatoxins production of A. parasiticus (3.18UdLTA) on PBM (pistachio based medium) under full dark (24 h), dark (12 h) and white light (12 h) and incubated conditions presented in Fig 1 . Irradiation doses are $1.7 \pm 0.2 \mathrm{~mW} / \mathrm{cm} 2$ and $0.1 \pm 0.2 \mathrm{~mW} / \mathrm{cm} 2$ for UV-A and UV-B. Different letters mean significant differences according to Tukey (HSD) test.

Fig 8. Aflatoxins (AFB1, AFB2, AFG1, and AFG2) distribution produced by A. parasiticus 3.18UdLTA on PBM (pistachio based medium) after 3 and $7 \mathrm{~d}$ under full dark (24 h), dark (12 h), and white light $(12 \mathrm{~h})$ and incubated conditions presented in Fig 1 . Irradiation doses are $1.7 \pm$ $0.2 \mathrm{~mW} / \mathrm{cm} 2$ and $0.1 \pm 0.2 \mathrm{~mW} / \mathrm{cm} 2$ for UV-A and UV-B. 

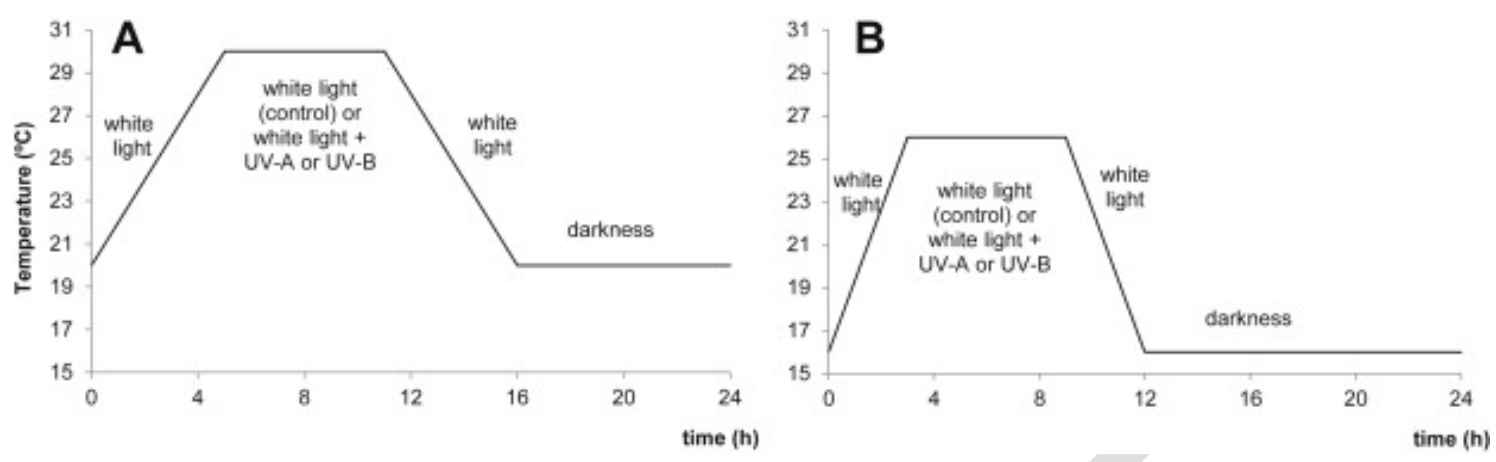


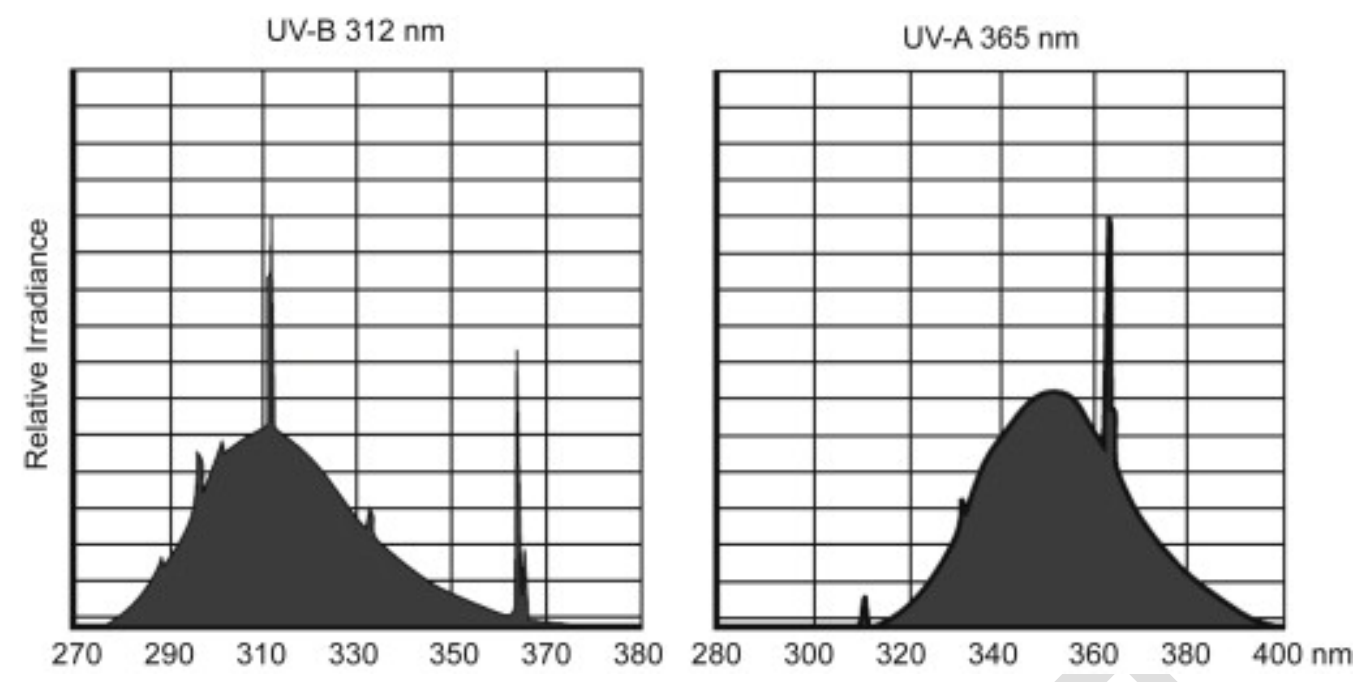



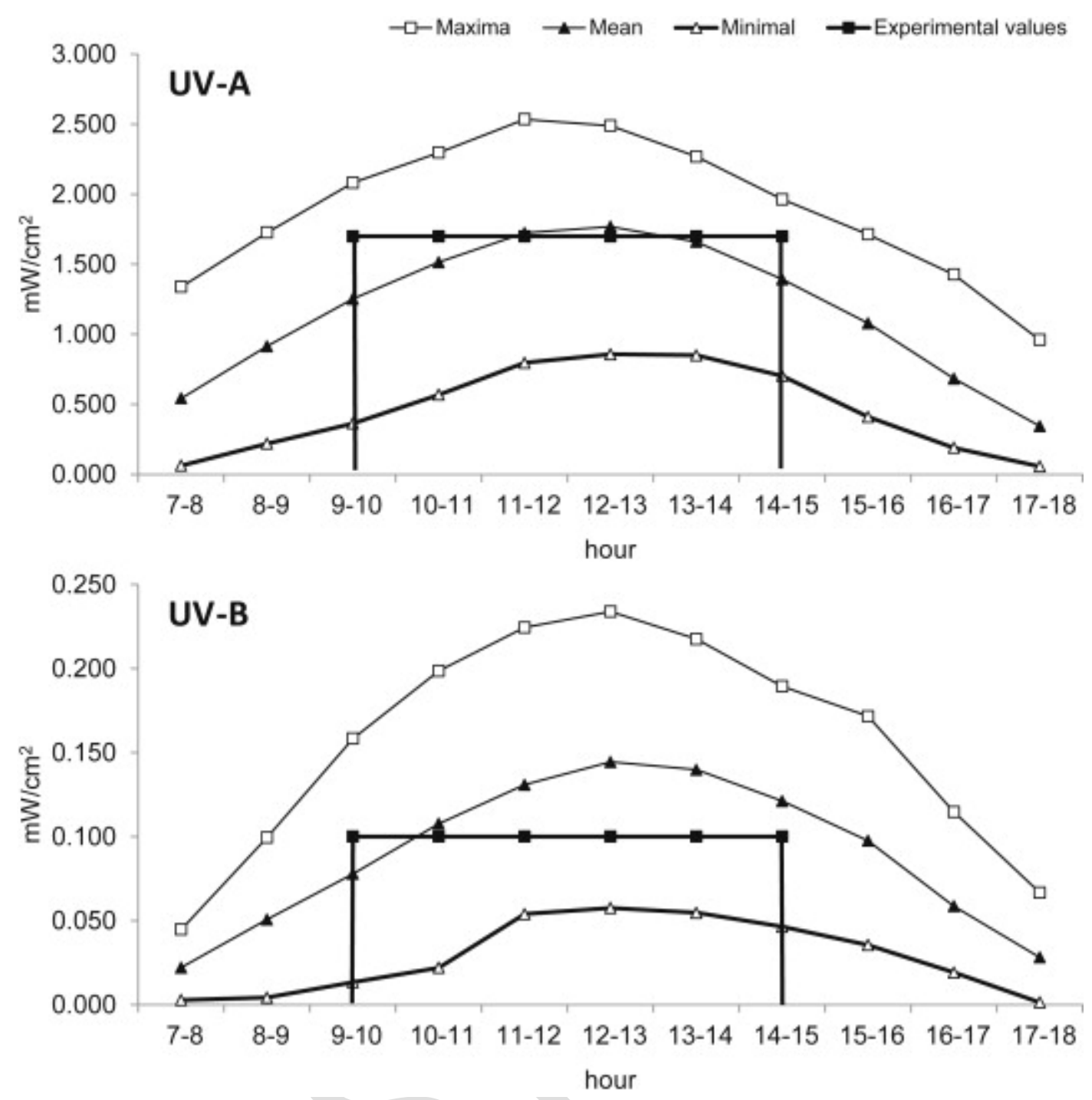


\section{Colony diameter}

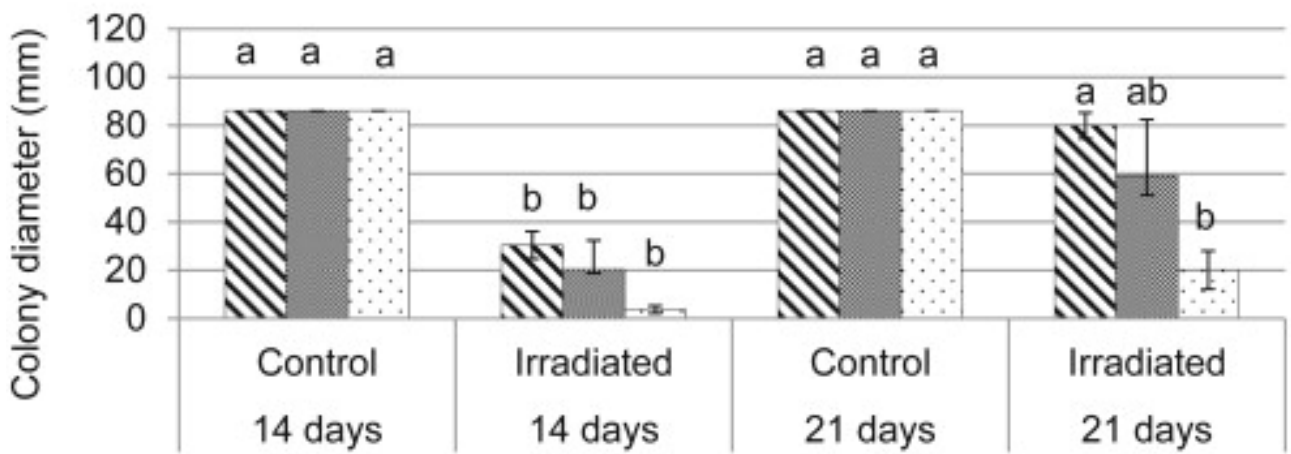

Biomass dry weight

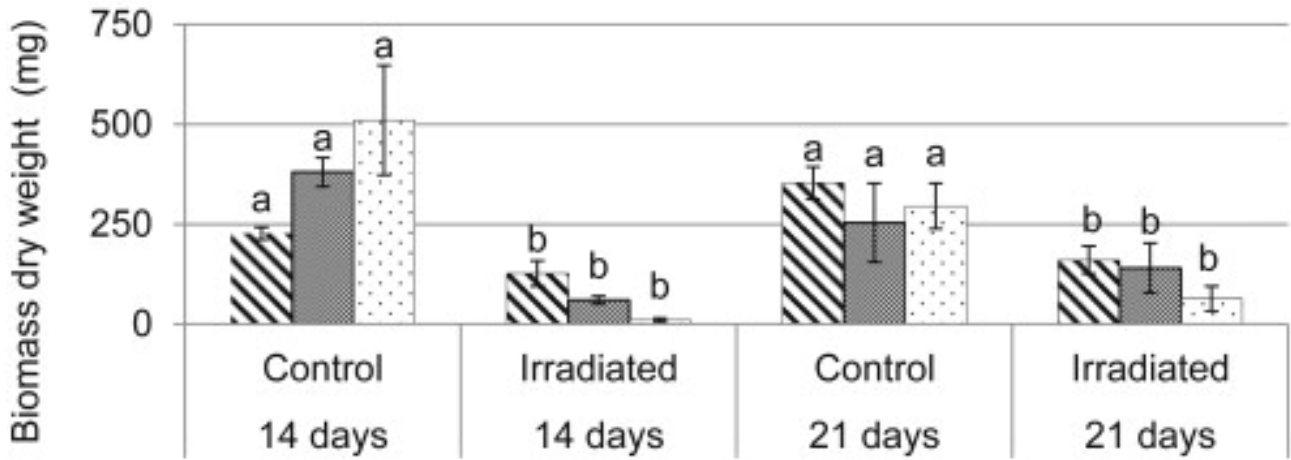

Ochratoxin A

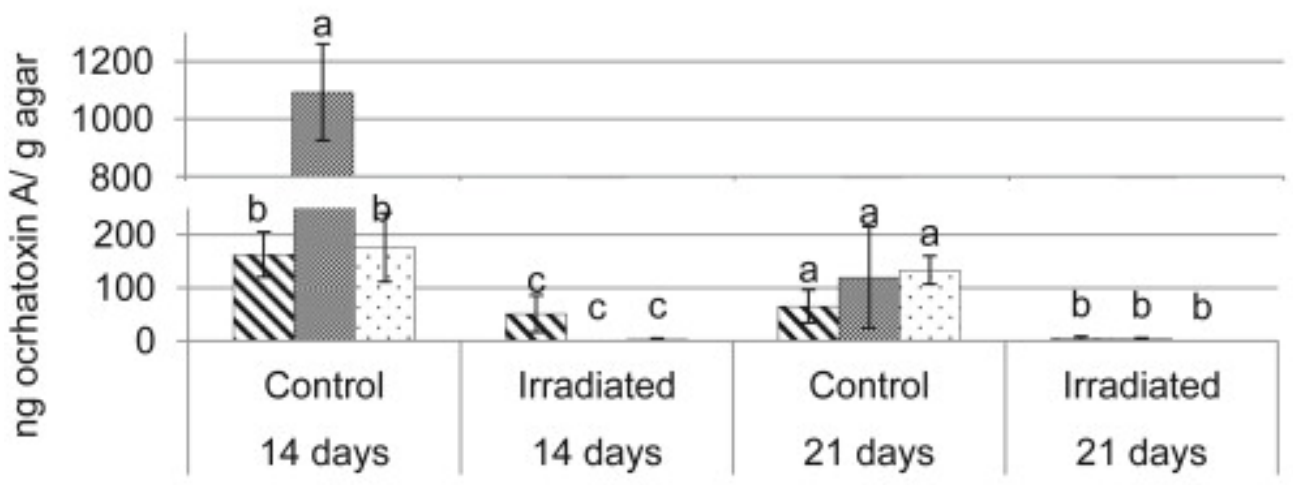

287-UdLTA $N \quad 311-U d L T A=318-U d L T A$ 

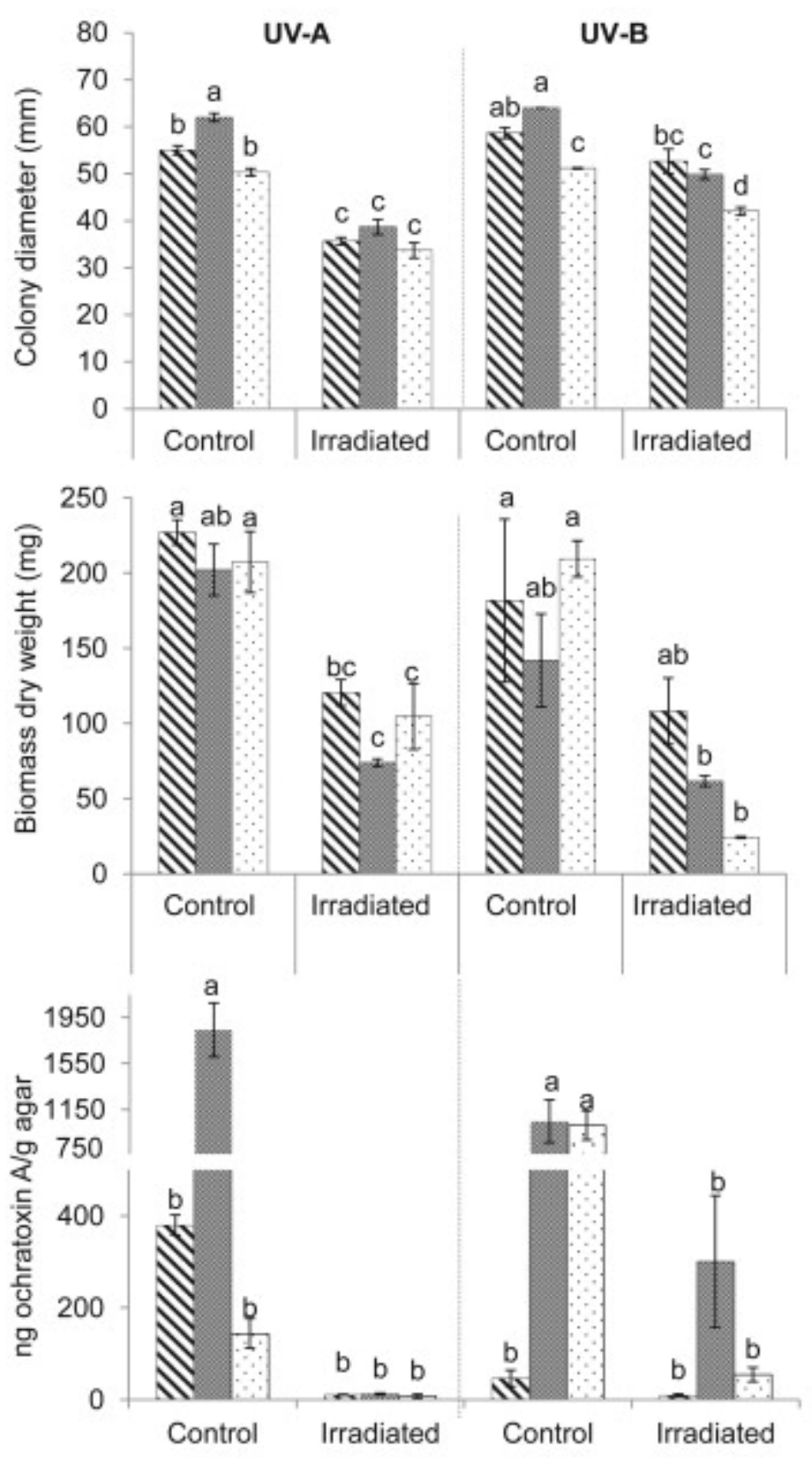

287 UdL-TA 311 UdL-TA 318 UdL-TA 

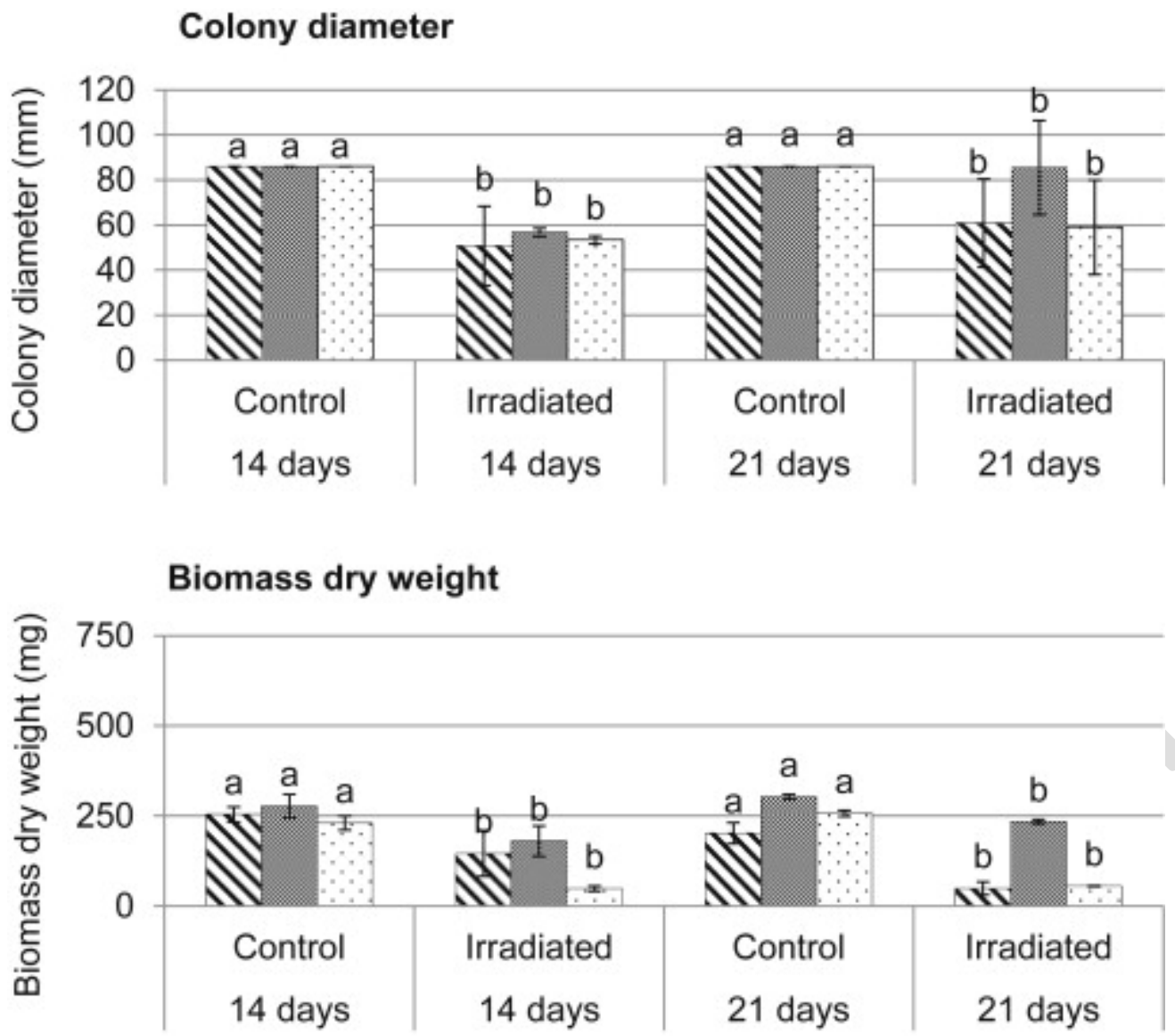

Ochratoxin A

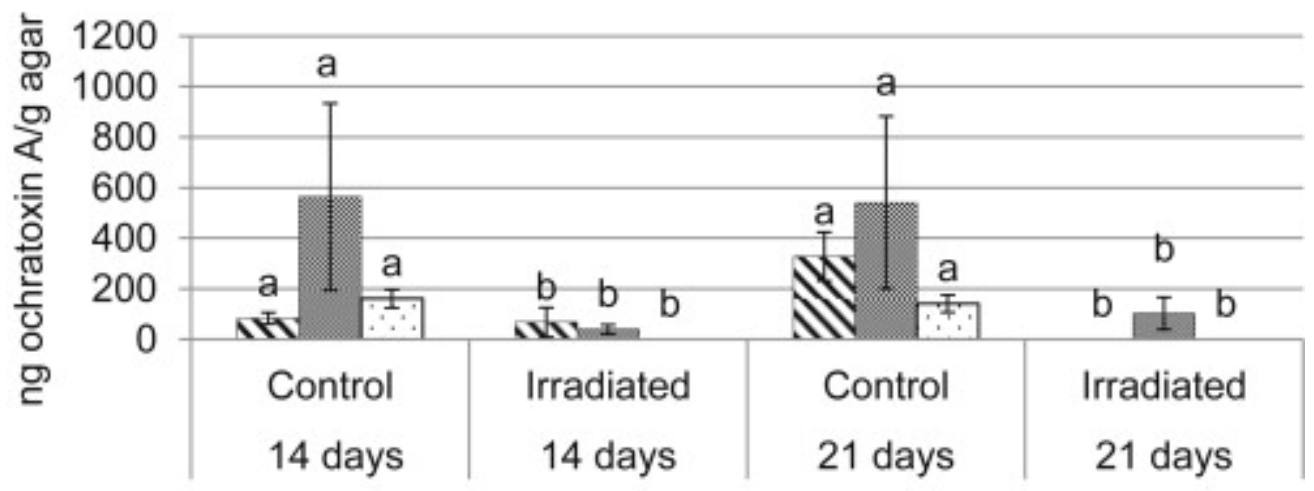

287-UdLTA N̦ 311-UdLTA $318-U d L T A$ 
UV-A

UV-B
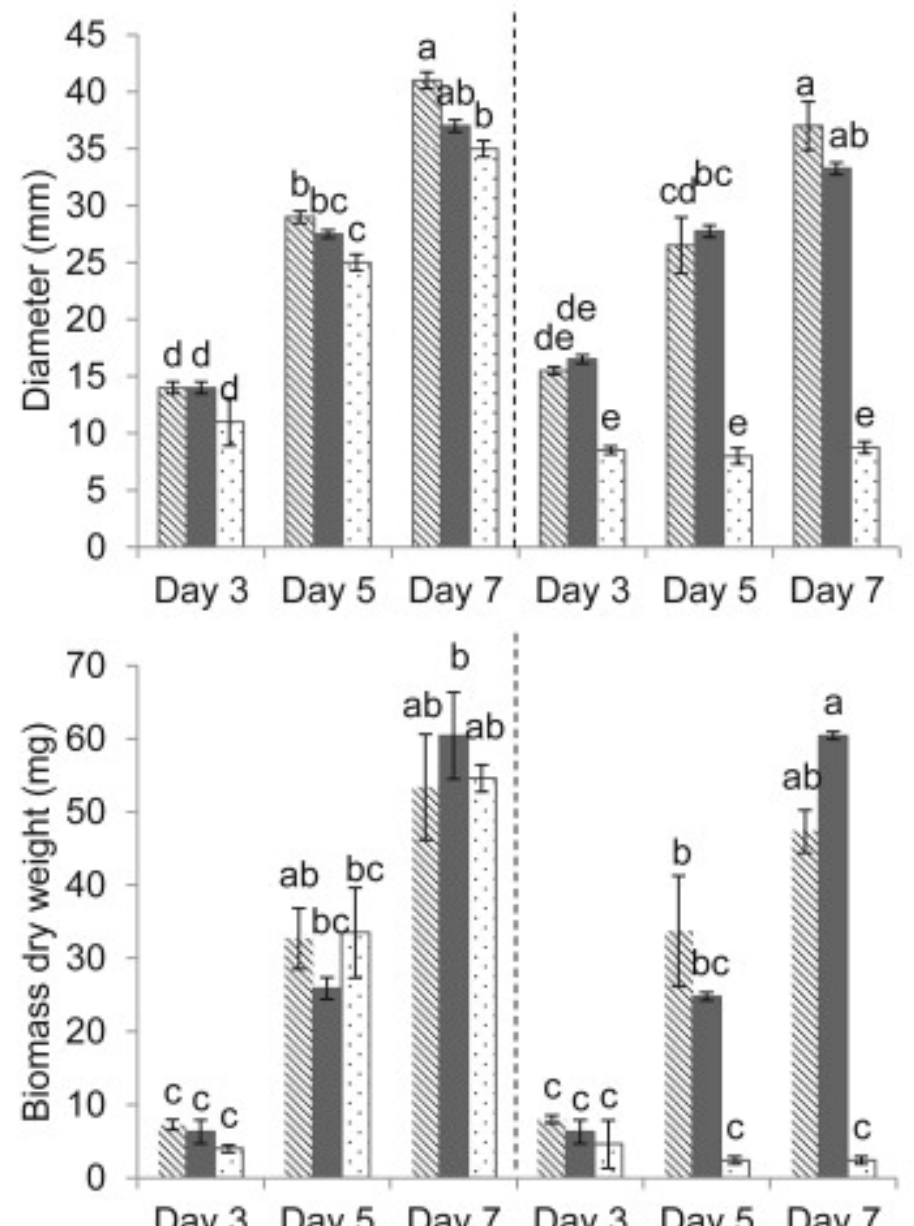

Day 3 Day 5 Day 7 Day 3 Day 5 Day 7

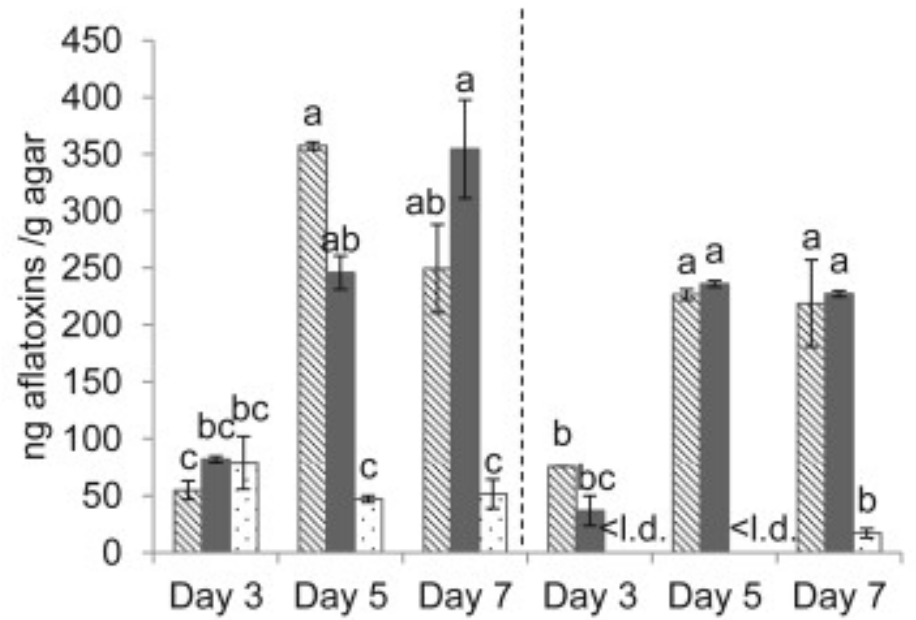

$\mathbb{N}$ Dark Dark+white light Dark+white light+UV 


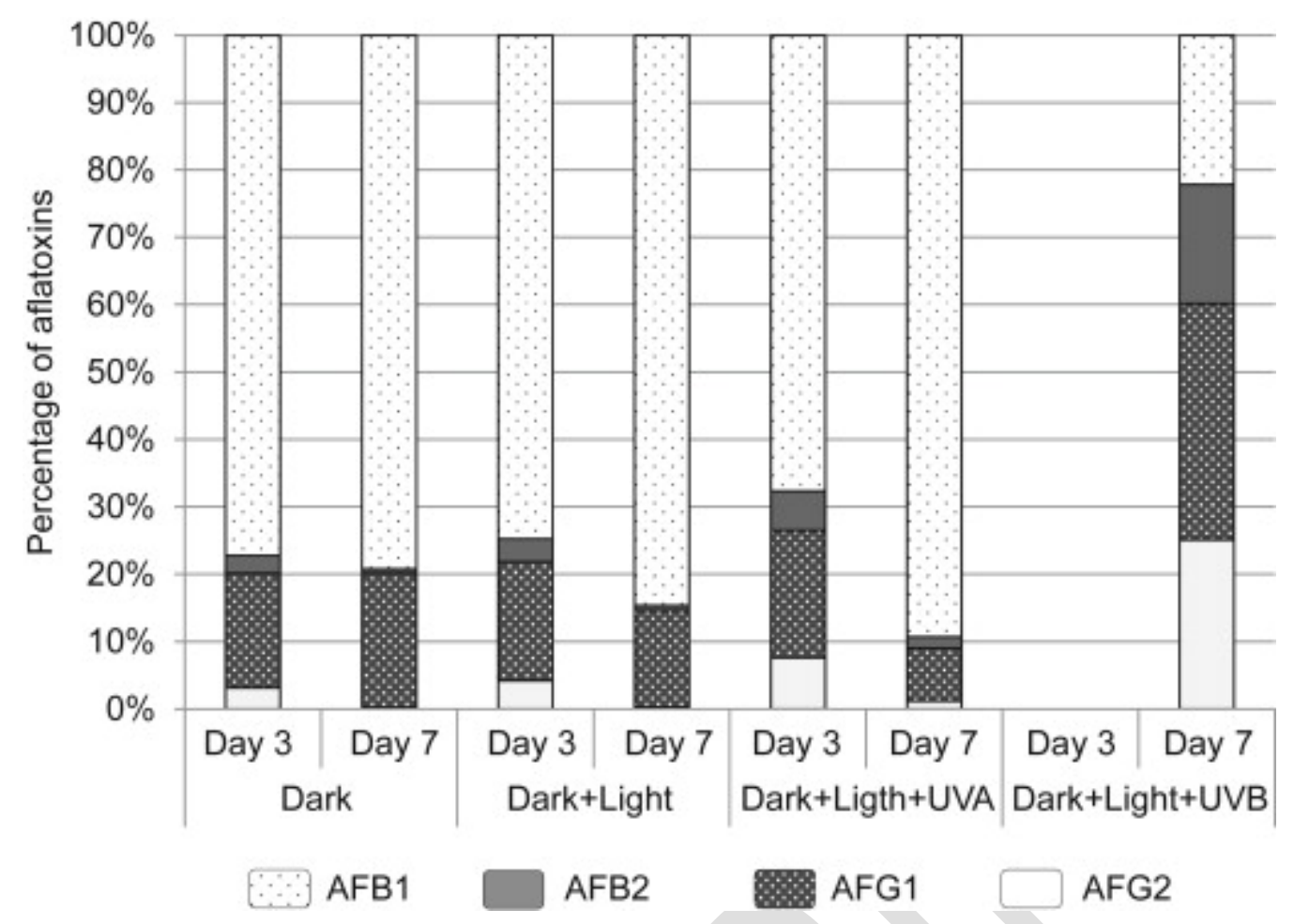


Table 1. Previously published studies regarding the effects of UV-A and UV-B radiation in fungi in laboratory conditions.

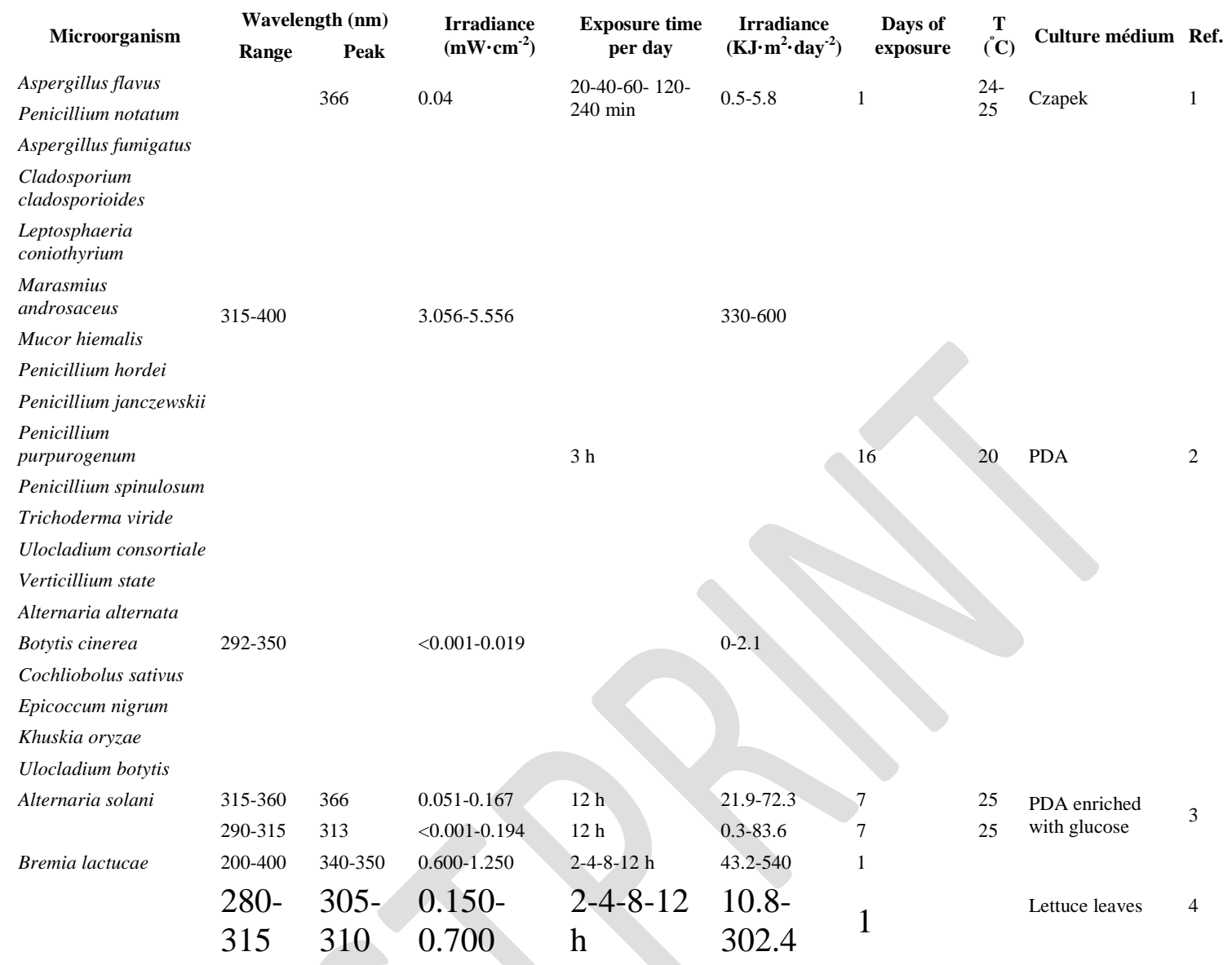

Data were obtained from the following references: (1) Osman et al., 1989, (2) Moody et al., 1999, (3) Fourtouni et al., 1998 and (4) Wu et al., 2000. 
Table 2. F values of main effects and their interaction in colony diameters, fungal dry weight biomass, OTA accumulation, and density of three $A$. carbonarius (287, 311, and 318-UdLTA) incubated on SNM (synthetic nutrient medium) for 14 and $21 \mathrm{~d}$.

\begin{tabular}{|c|c|c|c|c|c|c|c|c|}
\hline \multirow[b]{2}{*}{ Effects } & \multicolumn{4}{|c|}{ UV-A radiation } & \multicolumn{4}{|c|}{ UV-B radiation } \\
\hline & $\begin{array}{c}\text { Colony } \\
\text { diameter } \\
(\mathbf{m m})\end{array}$ & $\begin{array}{l}\text { Biomass dry } \\
\text { weight (mg) }\end{array}$ & $\begin{array}{c}\text { OTA } \\
\left(\operatorname{ng~g}^{-1}\right)\end{array}$ & $\begin{array}{l}\text { Colony density } \\
\left(\mathrm{mg} \mathrm{mm}^{-2}\right)\end{array}$ & $\begin{array}{c}\text { Colony } \\
\text { diameter } \\
(\mathbf{m m})\end{array}$ & $\begin{array}{l}\text { Biomass dry } \\
\text { weight (mg) }\end{array}$ & $\begin{array}{c}\text { OTA } \\
\left(\operatorname{ng~g}^{-1}\right)\end{array}$ & $\begin{array}{l}\text { Colony density } \\
\left(\mathrm{mg} \mathrm{mm}^{-2}\right)\end{array}$ \\
\hline Strain & $5.28^{*}$ & $0.03^{\mathrm{ns}}$ & $21.84^{* *}$ & $1.18^{\mathrm{ns}}$ & $1.03^{\mathrm{ns}}$ & $1.29^{\mathrm{ns}}$ & $1.50^{\mathrm{ns}}$ & $2.25^{\mathrm{ns}}$ \\
\hline Time & $10.00^{*}$ & $0.04^{\mathrm{ns}}$ & $13.72^{* *}$ & $4.17^{\mathrm{ns}}$ & $2.30^{\mathrm{ns}}$ & $1.40^{\mathrm{ns}}$ & $0.81^{\mathrm{ns}}$ & $2.32^{\mathrm{ns}}$ \\
\hline Treatment & $83.95^{* *}$ & $37.79^{* *}$ & $46.30^{* *}$ & $4.31^{*}$ & $26.10^{* *}$ & $5.57^{* *}$ & $5.77^{* *}$ & $2.14^{\mathrm{ns}}$ \\
\hline Strain $\mathrm{x}$ Time & $0.79^{\text {ns }}$ & $1.41^{\mathrm{ns}}$ & $12.58^{* *}$ & $1.36^{\mathrm{ns}}$ & $0.51^{\mathrm{ns}}$ & $0.55^{\mathrm{ns}}$ & $0.30^{\mathrm{ns}}$ & $2.39^{\mathrm{ns}}$ \\
\hline $\begin{array}{l}\text { Strain } \mathrm{x} \\
\text { Treatment }\end{array}$ & $5.28^{*}$ & $2.67^{\mathrm{ns}}$ & $18.54^{* *}$ & $1.14^{\mathrm{ns}}$ & $1.03^{\mathrm{ns}}$ & $0.32^{\mathrm{ns}}$ & $0.83^{\mathrm{ns}}$ & $2.26^{\text {ns }}$ \\
\hline $\begin{array}{l}\text { Time } \mathrm{x} \\
\text { Treatment }\end{array}$ & $10.00^{*}$ & $2.59^{\text {ns }}$ & $15.50^{* *}$ & $3.87^{\mathrm{ns}}$ & $2.30^{\mathrm{ns}}$ & $0.33^{\text {ns }}$ & $0.91^{\text {ns }}$ & $2.10^{\mathrm{ns}}$ \\
\hline $\begin{array}{l}\text { Strain } x \text { Time } \\
\mathrm{x} \text { Treatment }\end{array}$ & $0.79^{\mathrm{ns}}$ & $2.00^{\mathrm{ns}}$ & $14.08^{* *}$ & $1.23^{\mathrm{ns}}$ & $0.51^{\mathrm{ns}}$ & $0.07^{\mathrm{ns}}$ & $0.17^{\mathrm{ns}}$ & $2.36^{\text {ns }}$ \\
\hline
\end{tabular}

**, $p$-value $0.001 ; *$, $p$-value 0.05 ; ns, not significant. 
Table 3. F values of main effects and their interactions in colony diameters, fungal biomass, OTA accumulation, and density of three A. carbonarius (287, 311, and 318UdLTA) incubated on SNM (synthetic nutrient medium) for 14 and $21 \mathrm{~d}$.

\begin{tabular}{|c|c|c|c|c|c|c|c|c|}
\hline \multirow[b]{2}{*}{ Effects } & \multicolumn{4}{|c|}{ UV-A radiation } & \multicolumn{4}{|c|}{ UV-B radiation } \\
\hline & $\begin{array}{c}\text { Colony } \\
\text { diameter } \\
(\mathrm{mm})\end{array}$ & $\begin{array}{l}\text { Biomass dry } \\
\text { weight (mg) }\end{array}$ & $\begin{array}{c}\text { OTA } \\
\left(\text { ng g }^{-1}\right)\end{array}$ & $\begin{array}{l}\text { Colony density } \\
\left(\mathrm{mg} \mathrm{mm}^{-2}\right)\end{array}$ & $\begin{array}{c}\text { Colony } \\
\text { diameter } \\
(\mathbf{m m})\end{array}$ & $\begin{array}{l}\text { Biomass dry } \\
\text { weight (mg) }\end{array}$ & $\begin{array}{c}\text { OTA } \\
\left(\mathbf{n g ~ g}^{-1}\right)\end{array}$ & $\begin{array}{l}\text { Colony density } \\
\left(\mathrm{mg} \mathrm{mm}^{-2}\right)\end{array}$ \\
\hline Strain & $19.59^{* *}$ & $2.16^{\mathrm{ns}}$ & $34.16^{* *}$ & $12.88^{* *}$ & $29.93^{* *}$ & $1.85^{\mathrm{ns}}$ & $14.41^{* *}$ & $5.43^{*}$ \\
\hline Treatment & $326.64^{* *}$ & $64.00^{* *}$ & $73.08^{* *}$ & $1.61^{\mathrm{ns}}$ & $67.93^{* *}$ & $27.77^{* *}$ & $31.64^{* *}$ & $31.53^{* *}$ \\
\hline $\begin{array}{l}\text { Strain } \mathrm{x} \\
\text { Treatment }\end{array}$ & $3.13^{\mathrm{ns}}$ & $0.32^{\mathrm{ns}}$ & $33.88^{* *}$ & $1.01^{\mathrm{ns}}$ & $3.82^{\mathrm{ns}}$ & $1.28^{\mathrm{ns}}$ & $7.27^{* *}$ & $4.53^{* *}$ \\
\hline
\end{tabular}

**, $p$-value $0.001 ; *$, $p$-value 0.05 ; ns, not significant. 
Table 4. F values of main effects and their interactions in colony diameters, fungal biomass dry weight, AFs accumulation, and density of A. parasiticus (3.18-UdLTA) incubated on PBM (pistachio based medium) for $7 \mathrm{~d}$.

\begin{tabular}{|c|c|c|c|c|c|c|c|c|}
\hline \multirow[b]{2}{*}{ Effects } & \multicolumn{4}{|c|}{ UV-A radiation } & \multicolumn{4}{|c|}{ UV-B radiation } \\
\hline & $\begin{array}{c}\text { Colony } \\
\text { diameter } \\
(\mathbf{m m})\end{array}$ & $\begin{array}{l}\text { Biomass dry } \\
\text { weight (mg) }\end{array}$ & $\underset{\left(\text { ng g g }^{-1}\right)}{\text { AFs }}$ & $\begin{array}{c}\text { Density } \\
\left(\mathrm{mg} \mathrm{mm}^{-2}\right)\end{array}$ & $\begin{array}{c}\text { Colony } \\
\text { diameter } \\
(\mathbf{m m})\end{array}$ & $\begin{array}{l}\text { Biomass dry } \\
\text { weight (mg) }\end{array}$ & $\underset{\left(\mathrm{ng} \mathrm{g}^{-1}\right)}{\mathrm{AFs}}$ & $\begin{array}{c}\text { Density } \\
\left(\mathrm{mg} \mathrm{mm}^{-2}\right)\end{array}$ \\
\hline Time & $337.73^{* *}$ & $56.42^{* *}$ & $21.81^{* *}$ & $0.21^{\mathrm{ns}}$ & $52.14^{* *}$ & $39.43^{* *}$ & $36.62^{* *}$ & $0.08^{\mathrm{ns}}$ \\
\hline Treatment & $10.43^{*}$ & $0.00^{\mathrm{ns}}$ & $27.92^{* *}$ & $1.00^{\mathrm{ns}}$ & $105.90^{* *}$ & $41.22^{* *}$ & $72.66^{* *}$ & $0.03^{\mathrm{ns}}$ \\
\hline $\begin{array}{l}\text { Time } \mathrm{x} \\
\text { Treatment }\end{array}$ & $0.82^{\mathrm{ns}}$ & $0.51^{\mathrm{ns}}$ & $10.96^{* *}$ & $0.34^{\mathrm{ns}}$ & $12.79^{* *}$ & $13.09^{* *}$ & $8.53^{* *}$ & $0.42^{\mathrm{ns}}$ \\
\hline
\end{tabular}

**, $p$-value $0.001 ; *$, $p$-value 0.05 ; ns, not significant. 